\title{
Effectiveness of Scraping and Mitomycin C to Treat Haze After Myopic Photorefractive Keratectomy
}

\author{
Leopoldo Spadea ${ }^{*}$ and Valerio Verrecchia
}

\author{
Department of Surgical Sciences, University of L'Aquila, Eye Clinic, L'Aquila, Italy
}

\begin{abstract}
To report the possibility of post myopic photorefractive keratectomy (PRK) haze treatment in a patient with expressed reluctance for any additional laser therapy. Seven months after bilateral PRK with subsequent development of corneal haze and refractive regression in both eyes, a 37-old-year male patient presented a best-spectacle corrected visual acuity (BSCVA) of 20/30 in the right eye and of 20/22 in the left eye. Both eyes were sequentially treated by scraping the stromal surface and application of mitomycin $\mathrm{C}(\mathrm{MMC})$ for 2 minutes. Both eyes had significant improvement in corneal transparency. Eighteen months after this treatment BSCVA had improved to 20/20 in each eye. No toxic effects were observed during either re-epithelialization or follow-up periods. In conclusion scraping and application of MMC could be considered a good tool in the treatment of selected cases of haze after myopic PRK, especially with patients that are reluctant to undergo a secondary laser procedure.
\end{abstract}

Keywords: Mitomycin C, Haze, PRK, Scraping.

\section{INTRODUCTION}

Excimer laser photorefractive keratectomy has proven to be a safe and an effective technique to correct mild to moderate refractive errors. Haze formation with loss of corneal transparency, formation of surface irregularities, and myopic regression are the major complications after surfacebased corneal refractive surgery. There are several medical and surgical methods of managing haze. Initially the haze can be treated with topical steroids and topical non-steroidal anti-inflammatory drugs, especially in myopic eyes, but their efficacy over a long-time period is still controversial as they may also increase intraocular pressure (IOP) [1]. Haze can be treated with mechanical epithelial debridement or with laser-scrape [2]. Success of these procedures may depend on the morphology of the haze and on the patient's individual wound healing response. Manual debridement coupled with phototherapeutic keratectomy and mitomycin-C (MMC) can also be performed [3]. We present a case of a patient with a dense, visually significant reticular haze that developed approximately 3 months after myopic PRK. This patient also expressed reluctance for any additional laser therapy. This patient was treated by scraping the stromal surface to manually remove the irregular corneal tissue, followed by application of a diluted MMC solution on the stromal surface, to prevent further haze formation.

\section{CASE REPORT}

A 37-old-year male patient was seen who had received primary, bilateral PRK treatments by a surgeon using an InPro GmbH (Norderestadt, Germany) excimer laser to correct a refractive error of $-5.50=-1.50 . X .180$ in the right eye (RE) and -6.25 sphere in the left eye (LE). Seven months

*Address correspondence to this author at the Department of Surgical Sciences, University of L'Aquila, Eye Clinic, L'Aquila, Via Benozzo Gozzoli 34, 00142 Rome, Italy; Tel: +39/0862/319671;

Fax:+39/0862/434958; E-mail: 1spadea@cc.univaq.it after the initial treatment, the patient presented complaining of a reduction of the quality and quantity of visual acuity.

A complete ophthalmologic examination was performed with the RE showing uncorrected visual acuity (UCVA) of 20/400 and best spectacle-corrected visual acuity (BSCVA) of 20/30 with a manifest refraction of $-3.00=-1.50$.X.180. The LE had UCVA of 20/400 and a BSCVA of 20/22 with a manifest refraction of -4.00 sphere. The biomicroscopy examination showed an anterior stromal haze of grade 4 in both eyes (using the Heitzmann criteria (from 0 to 5).(Fig. 1A). The computerized videokeratography using a Keratograph (Oculus Optikgeräte GmbH, Wetzlar, Germany) showed evidence of irregular astigmatism (Fig. 2A). $50 \mathrm{MHz}$ ultrasound pachymetry (Corneo-Gage Plus ${ }^{\mathrm{TM}}$, Sonogage Inc., Cleveland, USA) elicited a minimum central corneal thickness of $583 \mu \mathrm{m}$ in the RE and of $582 \mu \mathrm{m}$ in the LE. Noncontact endothelial specular microscopy (Seed SP500, Seed Co., Tokyo, Japan) provided an endothelial cells density of 2882 cells $/ \mathrm{mm}^{2}$ in RE and 2760 cells $/ \mathrm{mm}^{2}$ in the LE. The scotopic pupil, evaluated by infrared pupillometry (Colvard, Oasis, Glendora, California, USA), was $5.5 \mathrm{~mm}$ in both eyes. Intraocular pressure, using Goldmann applanation tonometry, was $16 \mathrm{mmHg}$ in each eye. Fundus examination was within normal limits. The patient was reluctant to undergo a new laser treatment and therefore a bilateral, sequential, non-laser therapy was planned.

After obtaining appropriate informed consent, the treatments were performed using topical anesthesia with oxybuprocaine $0.4 \%$ drops and a sterile eyelid speculum was placed in the operative eye. Using a Desmarres corneal knife (Medtronic Ophthalmics, Jacksonville, Florida, USA), the epithelium was removed and then the corneal surface was scraped to remove as much scar as possible. Topical administration of $0.2 \mathrm{mg} / \mathrm{ml}$ mitomycin-C (MMC) diluted in balanced salt solution was then made by placing an $8-\mathrm{mm}$ diameter Hoffer Optic Zone Marker (Katena Products Inc., Denville, New Jersey, USA) onto the cornea. The solution 


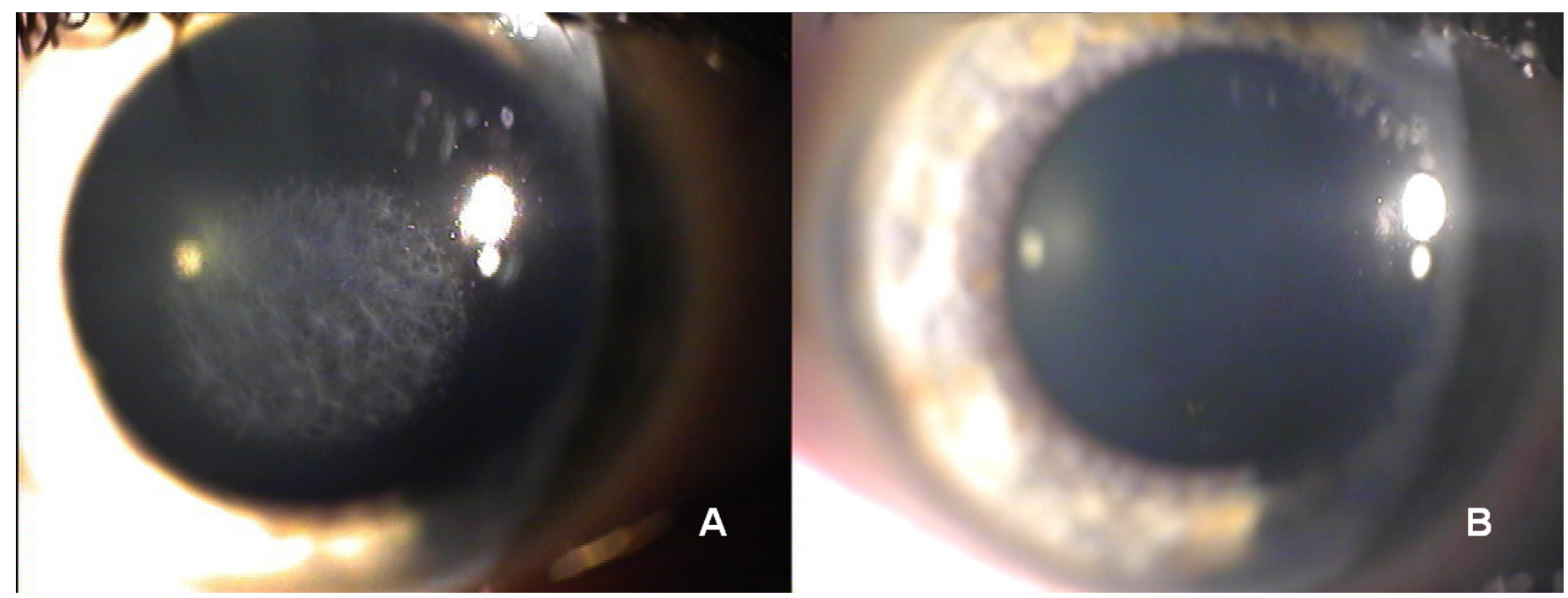

Fig. (1). Right eye slit lamp photographs before (A) and 18 months after (B) scraping of the stromal surface and application of MMC for treatment of post-PRK haze. The corneal clarity has remarkably improved.

was maintained in place for 2 minutes and then removed. The corneal surface and entire conjunctival sac were then vigorously irrigated using balanced salt solution (BSS Plus, Alcon Laboratories, Fort Worth, Texas, USA) to remove all MMC. After the treatment, a soft contact lens was applied as a bandage and a topical antibiotic agent (ofloxacin $0.3 \%$ ) and artificial tear drops (preservative free sodium hyaluronate $0.20 \%)$ were applied until re-epithelialization was completed (6 days). Topical corticosteroids (butyrate clobetasone $0.1 \%$ ) drops were administered for 3 months and then tapered and titrated. Follow-up examinations were scheduled at 1, 3, 6, 12 and 18 month after treatment. No side effects or toxic effects were detected during the follow-up period.

After eighteen months from the scraping and MMC application, the biomicroscopy evaluation showed clear corneas (haze grade 0.5) (Fig. 1B), and an associated low physiologic astigmatism in both eyes (Fig. 2B). The UCVAs were 20/32 and 20/100 respectively in RE and in LE, and the BSCVAs were 20/20 in both eyes (RE -1.75sph and LE $3.25 \mathrm{sph})$. The central corneal thickness decreased to $546 \mu \mathrm{m}$ in the RE and to $569 \mu \mathrm{m}$ in the LE. The endothelial cell count was unchanged $\left(2804\right.$ cells $/ \mathrm{mm}^{2}$ in RE and 2755 cells $/ \mathrm{mm}^{2}$ in LE). The patient reported an improved quality of visual acuity, and was satisfied with the results of the remediation.

\section{DISCUSSION}

Although PRK has proven to be safe and effective for a limited range of ametropias, use for correction of higher amounts of refractive error can lead to errant tissue reactions, which in turn can lead to corneal opacity and scar formation, called haze. In fact, although the technology has improved and some of the risk factors are now well known, haze remains the major complication after PRK. Corneal haze evidenced after an excimer laser treatment is characterized by disorganized sub-epithelial neocollagen constituted exnovo by mucuspolysaccharides and glycosamminoglicans synthesized by activated keratocytes [4]. The haze formation could consequently cause hypocorrection, astigmatism and myopic regression that may require retreatment.
Vigo et al. explored the possibility of treating haze by use of a cytostatic drug, mitomycin-C, after scraping the corneal surface to remove the corneal irregularity [5]. Applied on the cornea, mitomycin-C did not result in increased loss of keratocytes, but it significantly delayed keratocyte repopulation and activation in the anterior stroma with normal epithelial differentiation [6]. For these reasons MMC is a potent inhibitor of corneal scar formation (haze) induced by PRK.

The first phase of the technique used in the present case, scraping, must be vigorous and continuous until the corneal surface appears smoother and more homogeneous. In the second step, we administered the MMC in a new mode, by filling an 8-mm-diameter optic zone marker placed onto the cornea. This technique provides tighter contact of the solution to the stroma than by use of a Merocel sponge soaked with MMC. A proper dilution of the drug is crucial with the standard concentration of topical MMC $(0.02 \%)$ being more effective than a lower dose $(0.002 \%)$ in preventing postoperative haze following surface ablation for high myopia, without inducing any serious complications. The duration of MMC exposure appears to be less important than its concentration [7]. If the concentration is too high, the MMC may be toxic, producing opacity and corneal melting [8]. Administration of $0.02 \% \mathrm{MMC}$ applied for 12 seconds following PRK did not have a significant effect on quantitative endothelial cell density or qualitative morphometric parameters [9]. To the contrary, in a nonrandomized controlled trial, Nassiri et al. noted that the prophylactic use of diluted intraoperative MMC $0.02 \%$ solution caused corneal endothelial cell loss [10].

The present clinical case showed no side effects and corneal transparency has been maintained with no recurrence of haze for an extended period of 18 months. Therefore scraping and application of MMC could be considered a good tool for the treatment of selected cases of haze after myopic PRK, especially with patients that are reluctant to undergo a secondary laser procedure. 


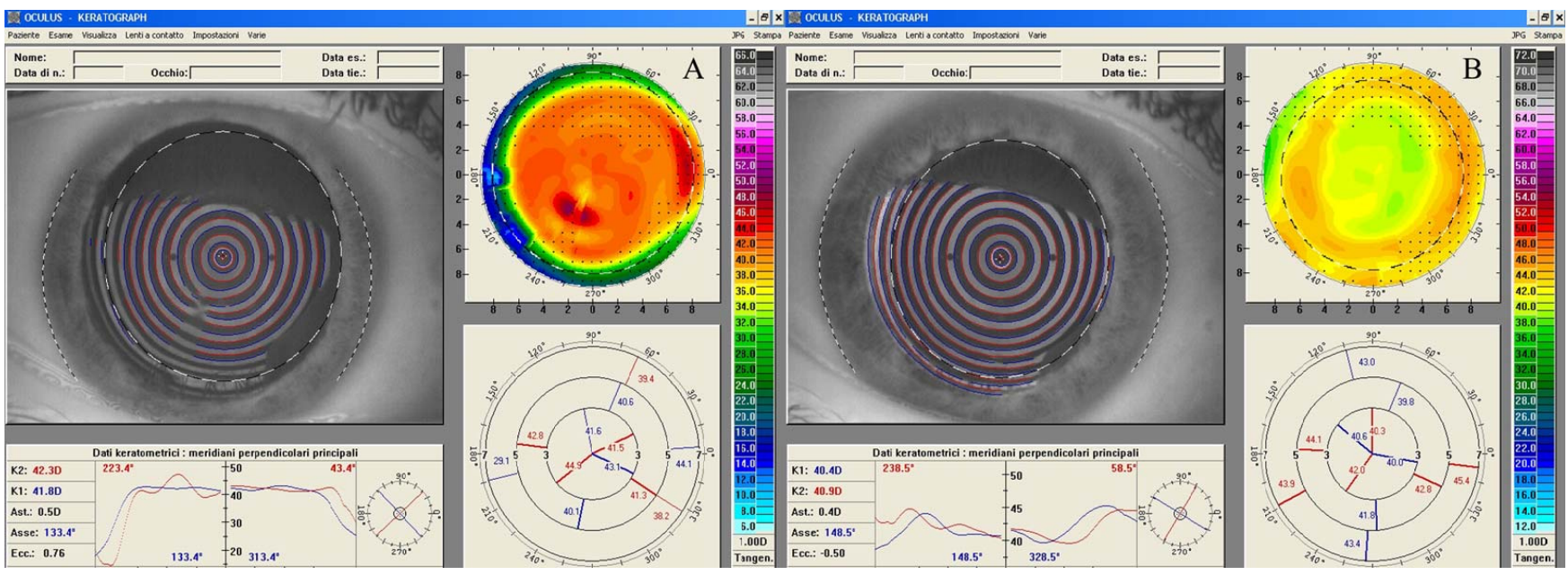

Fig. (2). Right eye videokeratography maps before (A) and 18 months after (B) scraping of the stromal surface and application of MMC for treatment of post-PRK haze. The topographic pattern highlights the improved corneal profile obtained (relative scale, tangential algorithm).

\section{ACKNOWLEDGEMENTS}

We want to thank Charles Wm. Stewart, OD for his contribute to review and edit the paper.

\section{CONFLICT OF INTEREST}

None of the authors have a financial or proprietary interest in any product or companies cited in this manuscript.

\section{REFERENCES}

Gartry DS, Kerr MMG, Lohmann CP, Marshall J. The effect of topical corticosteroids on refractive outcome and corneal haze after photorefractive keratectomy. A prospective, randomized, doubleblind trial. Arch Ophthalmol 1992; 110: 944-52.

[2] Lee YG, Chen WY, Petroll WM, Cavanagh HD, Jester JV. Corneal haze after photorefractive keratectomy using different epithelial removal techniques: mechanical debridement versus laser scrape. Ophthalmology 2001; 108: 112-20.

[3] Qazi MA, Johnson TW, Pepose JS. Development of late-onset subepithelial corneal haze after laser-assisted subepithelial keratektomy with prophylactic intraoperative mitomycin-C: case report and literature review. J Cataract Refract Surg 2006; 32: $1573-8$.
[4] Balestrazzi E, De Molfetta V, Spadea L, et al. Histological, immunohistochemical and ultrastructural findings in human corneas after photorefractive keratectomy J Refract Surg 1995; 11 : 181-7.

[5] Vigo L, Scandola E, Carones F. Scraping and mitomycin C to treat haze and regression after photorefractive keratectomy for myopia. J Refract Surg 2003; 19: 449-54.

[6] Rajan MS, O'Brart DP, Patmore A, Marshall J. Cellular effects of mitomycin-C on human corneas after photorefractive keratectomy. J Cataract Refract Surg 2006; 32: 1741-7.

[7] Thornton I, Xu M, Krueger RR. Comparison of standard (0.02\%) and low dose $(0.002 \%)$ mitomycin $\mathrm{C}$ in the prevention of corneal haze following surface ablation for myopia. J Refract Surg 2008; 24: S68-76.

[8] Dougherty PJ, Hardten DR, Lindstrom RL. Corneoscleral melt after pterygium surgery using a single intraoperative application of Mitomycin C. Cornea 1996;15: 537-40.

[9] Goldsberry DH, Epstein RJ, Majmudar PA, et al. Effect of mitomycin $\mathrm{C}$ on the corneal endothelium when used for corneal subepithelial haze prophylaxis following photorefractive keratectomy. J Refract Surg 2007; 23: 724-7.

[10] Nassiri N, Farahangiz S, Rahnavardi M, Rahmani L, Nassiri N. Corneal endothelial cell injury induced by mitomycin-C in photorefractive keratectomy: nonrandomized controlled trial. J Cataract Refract Surg 2008; 34: 902-8.

(C) Spadea and Verrecchia; Licensee Bentham Open.

This is an open access article licensed under the terms of the Creative Commons Attribution Non-Commercial License (http: //creativecommons.org/licenses/by$\mathrm{nc} / 3.0 /$ ) which permits unrestricted, non-commercial use, distribution and reproduction in any medium, provided the work is properly cited. 